\title{
Martine SONNET, Atelier 62
}

Cognac, Le Temps qu'il fait, 2008, 233 pages.

Michelle Zancarini-Fournel

\section{(2) OpenEdition}

Journals

Édition électronique

URL : http://journals.openedition.org/clio/9316

DOI : $10.4000 /$ clio.9316

ISSN : 1777-5299

Éditeur

Belin

Édition imprimée

Date de publication : 1 janvier 2009

Pagination : 267-268

ISBN : 978-2-8107-974-0

ISSN : $1252-7017$

Référence électronique

Michelle Zancarini-Fournel, « Martine sonnet, Atelier 62 », Clio. Histoire, femmes et sociétés [En ligne], 29 | 2009, mis en ligne le 11 juin 2009, consulté le 21 septembre 2020. URL : http://

journals.openedition.org/clio/9316; DOI : https://doi.org/10.4000/clio.9316

Ce document a été généré automatiquement le 21 septembre 2020.

Tous droits réservés 


\title{
Martine SONNET, Atelier 62
}

\author{
Cognac, Le Temps qu'il fait, 2008, 233 pages.
}

\author{
Michelle Zancarini-Fournel
}

1 Historienne moderniste, spécialiste de l'éducation des filles, Martine Sonnet nous offre ici un ouvrage sensible sur le parcours professionnel de son père, passé en 1951 de la campagne où il était artisan-forgeron à l'usine de Renault à Boulogne-Billancourt dans un poste d'OS et, finalement, dans un des ateliers parmi les plus durs, l'atelier 62, celui des forges.

2 Tel qu'il apparait sur la photographie de couverture, «le père » - haut, massif, mains dans les poches et cigarette au bec, encadré par un ouvrier immigré plus jeune marchant derrière lui et deux publicités l'une pour le viandox réparateur dégusté par une figure féminine, l'autre pour le vin rouge quotidien, source de force masculine semble incarner à lui seul la classe ouvrière virile, celle qu'affectionne Gérard Noiriel. Mais le livre de Martine Sonnet est bien autre chose qu'une étude objective du " groupe central ouvrier ». Si, contrairement à ce que nous propose la quatrième de couverture, l'ouvrage est AUSSI le travail d'une historienne sur les transformations sociales des Trente Glorieuses et l'expérience de l'usine, il est, frémissant d'émotions contenues, un récit subtil et empathique de la vie de travail de son père et également l'œuvre d'une écrivaine. Contrairement à Dominique Loiseau que 1968 a réconcilié avec la vie professionnelle de son ouvrier de père, Martine Sonnet écrit, elle, ne pas avoir fait le lien alors entre les chansons de Colette Magny ou de François Béranger qu'elle fredonnait dans les années 68 (dont Tango de l'ennui qui évoque la chaîne de Billancourt) et l'embauche de son père chez Renault. Ce n'est que vingt ans après sa mort survenue en 1986, qu'elle part à la recherche de cette vie de travail et de vie tout court entre campagne normande et banlieue parisienne.

3 Bien des historiens et historiennes du social peuvent envier les trois pages concises et précises du chapitre III intitulé « Métiers » où l'auteur énonce les dénominations des postes (« d'ajusteurs en matrice » à " tuyauteurs »), les classifications de l'entreprise depuis les "grilles Parodi-Croizat » en 1945 (manœuvres, OS, OP 1, 2, 3) - distinguées soigneusement des qualifications - réelles et symboliques (l'identité fière des hommes des forges, "les plus huppés » pour les OP Français, les OS étant Algériens) - 
confrontées à l'expérience vécue, transmise à l'insu du père et gardée par sa fille en souvenir. Confrontation édifiante entre mémoire familiale et discours des sciences sociales (celui, à partir de ses souvenirs, de l'ancien salarié de Renault, Daniel Mothé, devenu sociologue au CNRS). Tout au long du livre Martine Sonnet utilise son savoirfaire d'historienne pour recenser les divers écrits sur l'usine de Billancourt et les archives écrites et audiovisuelles, pour les analyser et les énoncer dans une langue superbe en les croisant avec son expérience sensible et ses souvenirs intimes. Du point de vue épistémologique, c'est une belle démonstration sur le récit historique, la mémoire et l'histoire, le rapport entre individu et collectif, le problème de l'expérience en histoire, toutes questions fondamentales traitées dans de savants livres et articles de philosophes et d'historiens. Je me hasarderai à une conclusion plus personnelle, induite par le livre : je l'ai lu d'une traite, toute une nuit, avec souvent les larmes au bord des paupières, tellement le récit me prenait à la gorge interpellant sans doute des interrogations personnelles relevant de l'intime. Au-delà de La Place d'Annie Ernaux qui actait la distance sociale construite par ses études entre elle et sa famille, l'ouvrage de Martine Sonnet comble, avec ses armes d'historienne et son écriture du sensible, le fossé entre sa filiation et ce qu'elle est devenue. Un beau livre et une leçon d'histoire. 